EPJ Web of Conferences 92,02111 (2015)

DOI: $10.1051 /$ epjconf/ 20159202111

(C) Owned by the authors, published by EDP Sciences, 2015

\title{
Experimental investigation of coarse particle conveying in pipes
}

\author{
Pavel Vlasak ${ }^{1 \mathrm{a}}$, Zdenek Chara $^{1}$, Jiri Konfrst ${ }^{1}$ and Jan Krupička ${ }^{1}$ \\ ${ }^{1}$ Institute of Hydrodynamics AS CR, v. v. i., Pod Patankou 30/5, Prague 6, Czech Republic
}

\begin{abstract}
The advanced knowledge of particle-water mixture flow behaviour is important for safe, reliable, and economical design and operation of the freight pipelines. The effect of the mixture velocity and concentration on the coarse particle - water mixtures flow behaviour was experimentally investigated on an experimental pipe loop of inner diameter $D=100 \mathrm{~mm}$ with horizontal, vertical, and inclined pipe sections. Narrow particle size distribution basalt pebbles were used as model of coarse-grained solid particles. The radiometric method was used to measure particle concentration distribution in pipe cross-section. Mixture flow behaviour and particles motion along the pipe invert were studied in a pipe viewing section. The study revealed that the coarse particlewater mixtures in the horizontal and inclined pipe sections were significantly stratified. The particles moved principally in a layer close to the pipe invert. However, for higher and moderate flow velocities the particles moved also in the central part of the pipe cross-section, and particle saltation was found to be dominant mode of particle conveying.
\end{abstract}

\section{Introduction}

Hydraulic transport pipelines are commonly used for transport of bulk materials, like coal, ores, waste materials, mostly relatively fine particles, which in the turbulent flow are supported by turbulent diffusion in the core of the flow. Near the pipe wall a lift force, associated with slip velocity and concentration profile contributed to particle lift-off. Pipeline transport of coarse-grained material is not very frequently used due to the problems of severe wear, material degradation, high deposition velocity limit and consequently also operational velocities, and energy consumptions. However, pipeline transport of coarse particles in form of heterogeneous mixtures is of potential importance in dredging and mining industry, e. g. the Alberta sands petroleum extraction, or poly-metallic nodules transport from the ocean bottom to the surface [1-3].

The understanding of the slurry flow behaviour makes it possible to optimize transport parameters and energy requirements, to improve quality, safety, economy and reliability of the transport. Knowledge of the slurry flow behaviour, deposition limit and operational velocities, and the pressure drops associated with the slurry flow in horizontal, vertical and inclined pipe sections is essential to safe and effective design and operation of such pipeline installation [2].

The flow of heterogeneous slurries in horizontal pipes may be defined as the flow with an asymmetrical concentration and velocity distribution, where a Coulomb friction contributes significantly to the friction losses. A flow pattern with a bed layer and a skewed concentration distribution generally exist for these slurries. The first mechanistic approach for coarse-grained particle slurry flow was probably that of Newitt et al. [4], who defined coarse particle conveyance as flow with a sliding bed and particle saltation.

Under this condition, turbulence and inter-granular contact are the two significant mechanisms of particle support. However, buoyancy and fluid forces cannot balance the weight for coarse particles; they are supported mainly by inter-granular contacts to the pipe wall. Mechanical forces of sliding or rolling contact must be countered by an additional pressure gradient, which is proportional to difference between slurry $\left(I_{S}\right)$ and carrier liquid $\left(I_{o}\right)$ pressure gradient. When the particle size is larger than the viscous sub-layer thickness, two forces help to particle movement in turbulent flow. The Magnus force is due to the particle rotation, Saffman force is due to the shear of the fluid itself, i. e. it induced the lateral lift force even if particle rotation is absent [5]. Campbell et al. [6] found, that this force, which generates from Bernoulli interaction, could be a significant fraction of the total weight of particles (about $40 \%$ ).

Wilson [7] proposed a two-layer model for settling slurries with fully stratified flow pattern, where all particles are supposed to be concentrated in the lower portion of the pipe, where concentration approaches the loose-packed value, and the Coulombic contribution to particle-wall friction is dominant. In the upper layer, only the carrier liquid is presented. Based on experimental data from the large test pipelines of the Saskatchewan Research Council the two-layer model was extended for finer particles [8]. The so called SRC two-layer model is

\footnotetext{
a Corresponding author: vlasak@ih.cas.cz
} 
based upon force balance for the upper and lower horizontal layers. All the above mentioned quantities, including the Reynolds number, friction factor and Coulomb type friction are defined for each layer as well as the interfacial friction factor and the flow parameters could be determined [9]. Because the layers differ in the solids concentration and velocity, there is a difference in the mean velocities of the particles and the liquid. Slip between the particles and the liquid results in a continuous transfer of energy from the fluid to the particle and from the particle to the pipe wall.

A lot of theoretical or experimental studies have been carried out on transport of sand or fine particles in horizontal pipes $[1,4,9-12]$. However, a relatively little research has been done on hydraulic conveying of gravel or bigger particles, especially in vertical and inclined pipes. A progress in the theoretical description of heterogeneous slurry flow is limited due to the lack of experimental data of the flow behaviour and an inner structure of slurry flow [13-14].

The present paper is focused on evaluation of the effect of average mixture velocity and overall concentration on the pressure drop versus the slurry average velocity relationship, on slurry flow behaviour and local concentration distribution.

\section{Experimental arrangements}

\subsection{Experimental pipe loop}

The experimental investigation was carried out on the pipe loop of inner diameter $D=100 \mathrm{~mm}$, which consists of smooth stainless steel pipes. The loop is suitable for studying the effect of mixture velocity and concentration on pressure drop and mixture flow behaviour in horizontal (A), inclinable and vertical (B) pipe sections [15], see figure 1 .

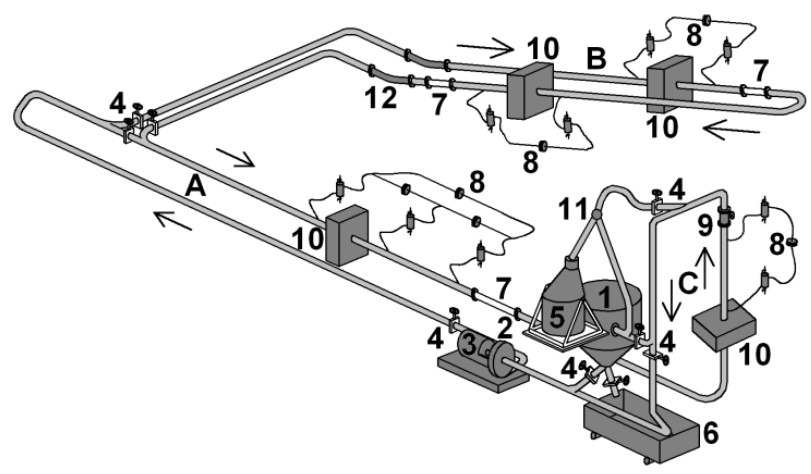

Fig. 1. Experimental test loop $D=100 \mathrm{~mm}$ at the Institute of Hydrodynamics AS CR, v. v. i., Prague.

Slurry was prepared in a mixing tank (1) and pumped into the test loop by a centrifugal slurry pump GIW LCCM 80-300 (2) with variable speed drive Siemens 1LG4283-2AB60-Z A11 (3) with the maximum power of $90 \mathrm{~kW}$. The pressure drop, $I_{s}$, were measured by the differential pressure transducers Rosemount 1151DP (8) over 2-meter long measuring sections located in the horizontal and the ascending- and descending measuring sections, which are fully inclinable from horizontal to vertical. The mean slurry velocity, $V_{s}$, was measured in a broad range from about $1.5 \mathrm{~m} \mathrm{~s}^{-1}$ close to deposition limit velocity $\left(V_{c r} \approx 1 \mathrm{~m} \mathrm{~s}^{-1}\right.$ ), to maximum values about 5.5 $\mathrm{m} \mathrm{s}^{-1}$ by a Krohne magnetic flow meter OPTIFLUX 5000 (9), mounted in the short vertical section (C) at the end of the loop.

Transparent viewing pipe sections (7) for visual observation are situated just downstream the measuring sections in the horizontal (A), and in inclinable (B) sections. In the pipe viewing section the mixture flow was recorded using a high speed digital camera NanoSence MK III+ with a frequency up to 2000 frames per second, image resolution $1280 \times 1024$ pixels and frame rate $200 \mathrm{~Hz}$. The record length was 3272 frames (16.36 s).

The flow divider (11) allows collection of slurry samples in the calibrated sampling tank (5) and measuring of the delivered concentration, $c_{v}$, and flow rate $Q$. The vertical U-tube (B) enables evaluating the delivered concentration of solid phase. To measure local concentration of solids, the loop is equipped with radiometric density meters (10) placed on a special support controlled by the computer. The support serves for vertical linear positioning of both the source and the detector to measure vertical concentration profiles. To determine local concentration distribution through the pipe cross-section the parallel projections of $\gamma$-ray beam were provided at several angles around the pipe axis (i.e. step of $15^{\circ}$ from zero to $165^{\circ}$ ), and collected data were processed by computer tomography method. The radiometric density meters consist of a $\gamma$-ray source (Caesium ${ }^{137} \mathrm{Cs}$, activity $740 \mathrm{MBq}$ ) and of a detector (a scintillating crystal of $\mathrm{NaI}(\mathrm{Tl})$ ). A multi-channel digital analyser enables an evaluation of the energy spectrum of the detected signal. The radiometric device was mounted upstream of the measuring and viewing sections in the horizontal or inclinable sections of the loop.

Measurement of the local concentration map is rather time consuming, however it made possible to evaluate effect of the mixture velocity and mean concentration on solids distribution in pipe cross-section [16].

\subsection{Measured material}

The studied mixtures consist of graded basalt pebbles of narrow particle size distribution (particle diameter, $d$, ranged from 8 to $16 \mathrm{~mm}$, mean diameter $d_{50}=11.0 \mathrm{~mm}$, density $\rho_{p}=2787 \mathrm{~kg} \mathrm{~m}^{-3}$ ), see figure 2 . The originally angular basalt gravel quickly degraded and formed a round shape during measurements.

The effect of the solid material degradation appears mainly for mixture velocities exceeding $3 \mathrm{~m} / \mathrm{s}$ and for higher mean concentration values. After short pumping times at velocities around $3.5 \mathrm{~m} \mathrm{~s}^{-1}$, the particle shape and size became practically stabilized. The particle size distribution is presented in figure 3 . The mean particle diameter changed from the original value $d_{50}=11.7 \mathrm{~mm}$ to $d_{50}=11.0 \mathrm{~mm}$ (about $94 \%$ of the original value), and the mass proportion of particles smaller than $5 \mathrm{~mm}$ did not exceed $10 \%$ [17]. 

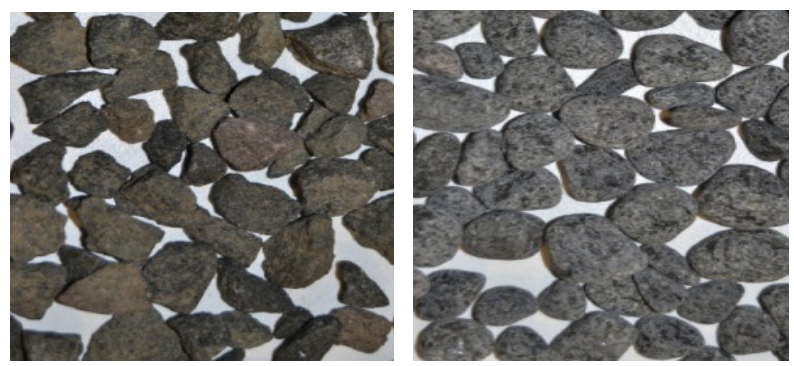

Fig. 2. The graded basalt pebbles; original (left $-d_{50}=11.7$ $\mathrm{mm}$ ) and after degradation (right $-d_{50}=11.0 \mathrm{~mm}$ ).

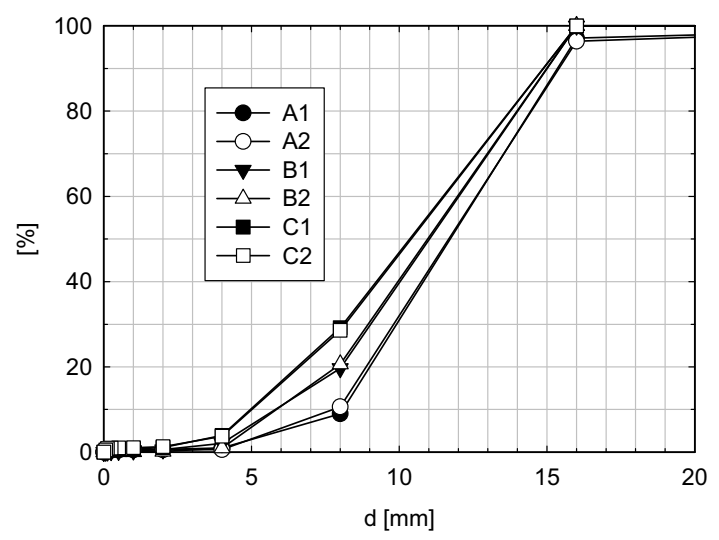

Fig. 3. Effect of pumping on particle size distribution of graded basalt pebbles (A1, A2 - original sample; B1, B2 $c_{v}=5 \%$, after 1.5 and 4 hours of pumping, respectively; $\mathrm{C} 1, \mathrm{C} 2$ - after 3 hours of pumping, $c_{v}=9 \%$ and $14 \%$, respectively).

Water was used as a carrier liquid and the overall concentration, $c_{v}$, ranged from 3 to $15 \%[18]$.

\section{Pressure drop}

Effect of mixture concentration and velocity on frictional pressure drop in horizontal and vertical pipe section is illustrated in figure 4.

\subsection{Horizontal pipe}

Practically parallel course of mixture pressure dropvelocity dependence $I_{s} / V_{s}$ with that of water alone confirmed an assumption that for fully stratified mixtures the main proportion of frictional pressure drop was due to the Coulomb friction between the particles and the pipe wall.

The frictional pressure drop in the horizontal pipe section were significantly higher than that in the vertical pipe due to the fact, that for stratified flow the contact load produced significant energy losses [17].

\subsection{Vertical pipe}

The experimental result did not confirm assumptions of some authors [19] about the almost negligible effect of the course particles on the frictional pressure drop in vertical pipe. They assumed that particles in the vertical pipe concentrate in core portion of the pipe. Thus, when the particles moved mostly in core of the pipe, mixture behaves like carrier liquid alone and frictional pressure drops were produced mainly by pipe wall-liquid friction, and share of inner friction and drag between particles and liquid becomes less important. The present results show, that the frictional pressure drop of coarse-grained mixtures in vertical pipe increases with the increasing concentration, similarly to results of Chung et al. [20] and Sumardi and Chung [21]. The hydrostatic effect $\Delta p=\left(\rho_{s}-\rho_{0}\right) \cdot g . \Delta h$, where $\rho_{s}$ and $\rho_{\mathrm{o}}$ is density of the mixture and carrier liquid, respectively, and $\Delta h$ is height of the mixture column, was extracted in figure 4 . It was revealed that the frictional pressure drop in vertical pipe increased with increasing mixture velocity, what confirmed effect of inner friction, inter-particles collision, and the drag due to particle-liquid slip.
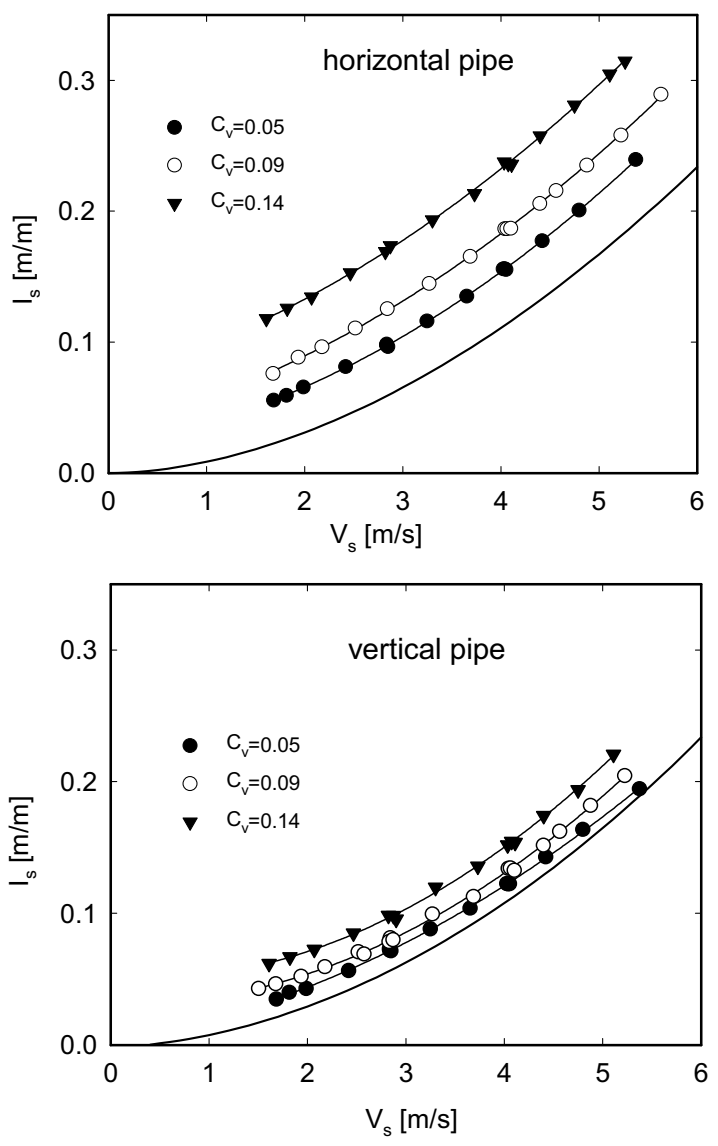

Fig. 4. Effect of transport concentration, $c_{v}$, and mean velocity, $V_{s}$, on pressure drop, $I_{s}$, in the horizontal and vertical pipe sections. Basalt pebble-water mixture, $D=100 \mathrm{~mm}$.

\subsection{Inclined pipe}

The pressure drop in inclined pipe can be described by well-known Worster and Denny [22] formula, and can be divided into two parts - not recoverable frictional pressure drop, and the hydrostatic pressure difference, in principle change of potential energy. Figure 5 illustrates effect of the pipe inclination, $\alpha$, on pressure drop, $I_{s}$, in inclined pipe sections for different values of mixture transport concentration and mean velocity, $V_{s},[18,23]$. 

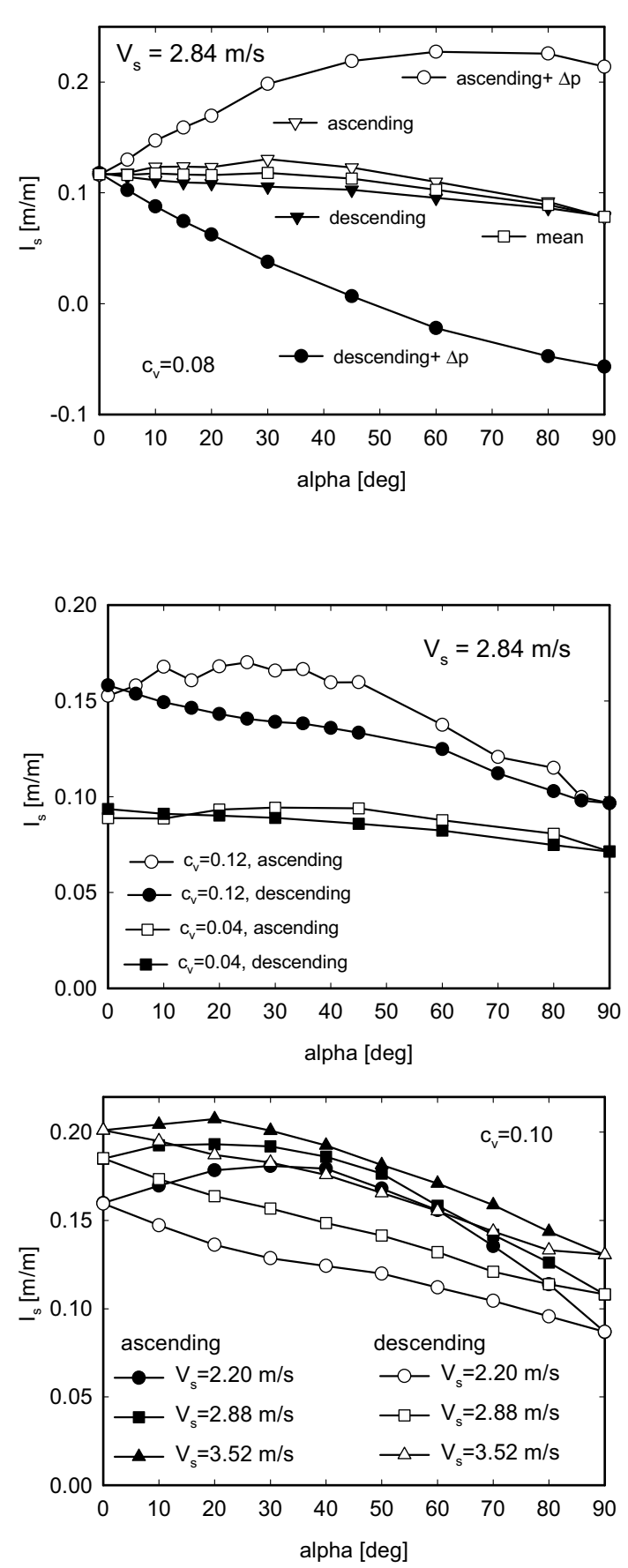

Fig. 5. Effect of mixture velocity, $V_{s}$, and pipe inclinaion, $\alpha$, on frictional pressure drop, $I_{s}$. Basalt pebble-water mixture, $D=100 \mathrm{~mm}$.

It was found that for stratified coarse-grained mixture the frictional pressure drop was not significantly influenced by the pipe inclination, especially for low concentration values. The effect of pipe inclination decreased with increasing mixture velocity in ascending pipe section; the maximum value was reached for inclination from $20^{\circ}$ to $40^{\circ \circ}$. Inclination of pressure drop maximum increased with decreasing mixture velocity. In descending pipe section the frictional pressure drop gradually decreased with increasing pipe inclination. The effect of inclination on frictional pressure drops could be practically neglected, especially for low mixture concentration and higher flow velocities. Similar results were found by Kao and Hwang [13] for coal $\left(d_{50}=1.40 \mathrm{~mm}\right)$ or glass beads $\left(d_{50}=0.66 \mathrm{~mm}\right)$ in pipe of $D=50 \mathrm{~mm}$ and mixture velocity ranged from 1.3 to $2.6 \mathrm{~m} \mathrm{~s}^{-1}$.

\section{Mixture flow behaviour}

From visualization of the coarse-grained mixtures flow we found, that individual particles slid and rolled along the pipe invert for mixture velocities about deposition limit. With increasing velocity bottom formations similar to dunes originated [19]. For velocity interval from about 1.5 to $2.5 \mathrm{~m} \mathrm{~s}^{-1}$ dunes disaggregated, thickness of the bed formations decreases and continuous sliding bed layer was observed.

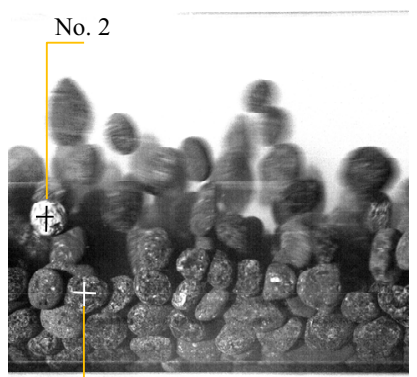

No. 1

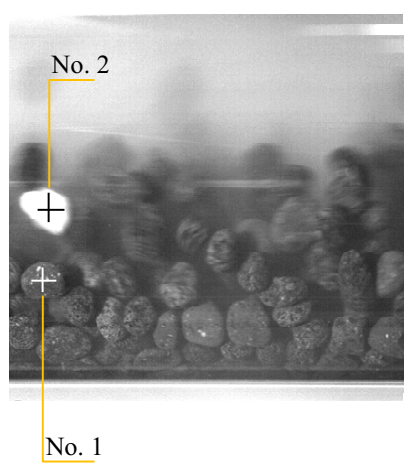

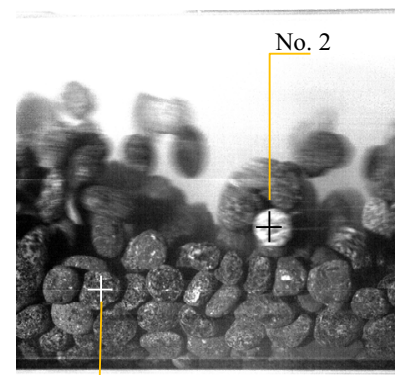

No. 1

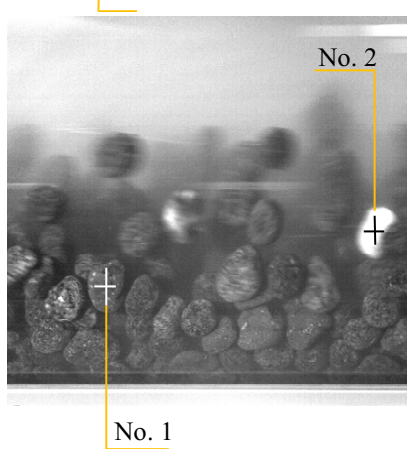

Fig. 6. Particles movement along the pipe invert. $V_{s}=1.04$ and $1.35 \mathrm{~m} \mathrm{~s} \mathrm{~s}^{-1}$, respectively. Basalt pebble-water mixture, $D=100 \mathrm{~mm}$.

For low mixture velocities (e.g. $V_{s} \approx 1.05 \mathrm{~m} \mathrm{~s}^{-1}$ ) a stationary bed was originated, where two layers of the bed can be distinguished. Close to pipe invert particles were motionless, see e. g. particles in vicinity of particle No. 1 in figure 6 above. Particle No. 2 and others in the upper layer of the bed were moving, and above the "compact" bed, particles moved relatively quickly in saltation mode. With increasing velocity (e.g. $V_{s} \approx 1.45 \mathrm{~m} \mathrm{~s}^{-1}$ ), even particles close the pipe invert start slowly to move, see particle No. 1 in figure 6 below, particles in the upper layer move more quickly (see e.g. particle No. 2), however the upper layer became thinner and more particles passed to saltation mode; with increasing mixture velocity more and more particles lifted off the pipe bottom, moved in saltation or even suspended mode [24].

For moderate and higher flow velocities, particles saltation became dominant mode of particle conveying $[15,25-26]$, the particles moved in saltation mode with only temporal contact with pipe bottom and walls. 
Velocities of the saltating particles were significantly higher than that of the sliding or rolling particles, moving in contact with the pipe wall. However, most of the particles were concentrated in lower portion of the pipe and moved in saltation mode with intensive rotation.

The mutual particle-particle and particle-pipe interactions and collisions resulted in significant increase of the total pressure drop. The relatively high value of slip velocity between conveyed particles and carrier liquid, mutual particle-particle and particle-pipe interactions and collisions resulted in significant increase of the total pressure drop $[3,27]$.

\section{Concentration distribution}

Distribution of the local concentration in the pipe crosssection is important for understanding the physical mechanism of the heterogeneous mixture flow; it has a great effect on both the mixture's flow behaviour and pressure drop. The concentration distribution in a horizontal pipe section was measured using of a $\gamma$-ray device and the effects of mixture velocity and concentration on the chord-averaged concentration profiles were analysed.

\subsection{Chord-averaged concentration profile}

Figure 7 presents effect of the mean mixture velocity, $V_{s}$, and/or mean transport concentration, $c_{v}$, on the vertical profile of chord-averaged in situ volumetric concentration, $C_{i n}$. The measured concentration profiles confirmed stratified flow pattern of the measured coarse particle-water mixture.

The concentration profiles can be divided on three parts. In the upper portion of the pipe, the local concentration tends to approach zero. Near the pipe invert, solids concentration reached maximum, and for the higher mixture velocity a thin layer with nearly constant local concentration is formed. The zero concentration region increases with decreasing mixture velocity, on the contrary the bottom region of high local concentration increases with increasing mixture velocity. Nearly linear concentration distribution can be recognized in the central portion of the pipe. Slope of this dependence slightly decreases with increasing mixture velocity.

For low mixture velocity, $V_{s}=1.8 \mathrm{~m} \mathrm{~s}^{-1}$, no bed layer was observed. With increasing mean concentration, the liquid alone area became smaller, from about 0.6 to $0.3 \mathrm{~h}$. A similar shape of chord-averaged concentration profiles was observed for moderate mixture velocity $V_{s}=2.8$ $\mathrm{m} \mathrm{s}^{-1}$; a bed layer with the mean concentration nearly $50 \%$ was observed in height $h$ from 10 to $12 \mathrm{~mm}$ from the pipe invert for the mean mixture concentration about $12 \%$. For this moderate flow velocity an intensive particle saltation was observed. With increasing mixture velocity, for $V_{s}=4.1 \mathrm{~m} \mathrm{~s}^{-1}$, particle saltation became dominant mode of particle movement; the layer of higher concentration extended up to height $h$ about $20 \mathrm{~mm}$, however maximum chord-averaged concentration value decreased to about $25-45 \%$.
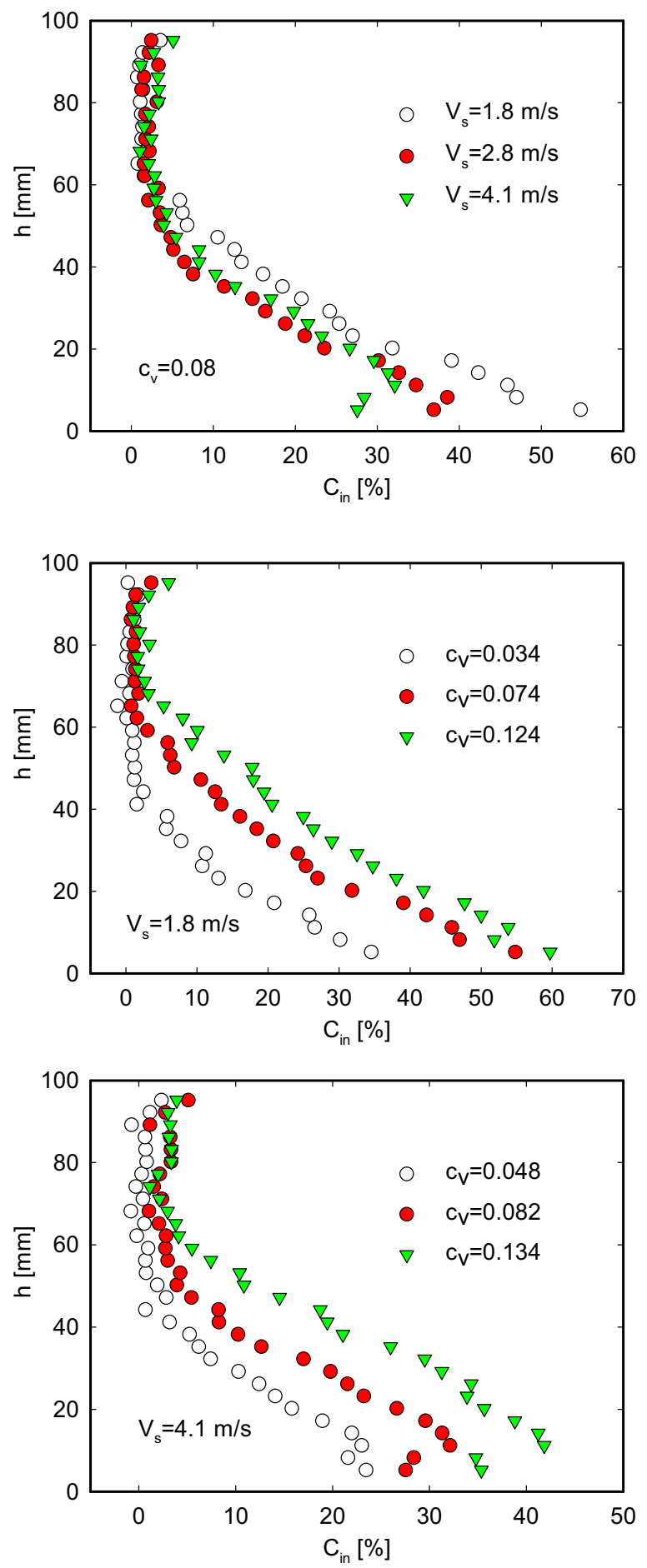

Fig. 7. Vertical profiles of chord-averaged local in situ volumetric concentration, $C_{i n}$ in horizontal pipe, effect of transport concentration $c_{\mathrm{v}}$ and mixture flow velocity, $V_{s}$.

No concentration values close to the loose-packed value were observed for moderate and higher mixture velocity. Based on conducted measurement it is evident that coarse particles tend to occupy the bottom part of the pipe. However, when mixture velocities extended enough the deposition limit, the solid particles moved commonly over the whole pipe cross-section. Observed chordaveraged concentration profiles are in good agreement with these measured by Pugh and Wilson [28], Kaushal 
and Tomita [29], Matousek [30] or Sobota et al. [31], for heterogeneous mixtures with smaller particle diameters.

\subsection{Local concentration maps - horizontal pipe}
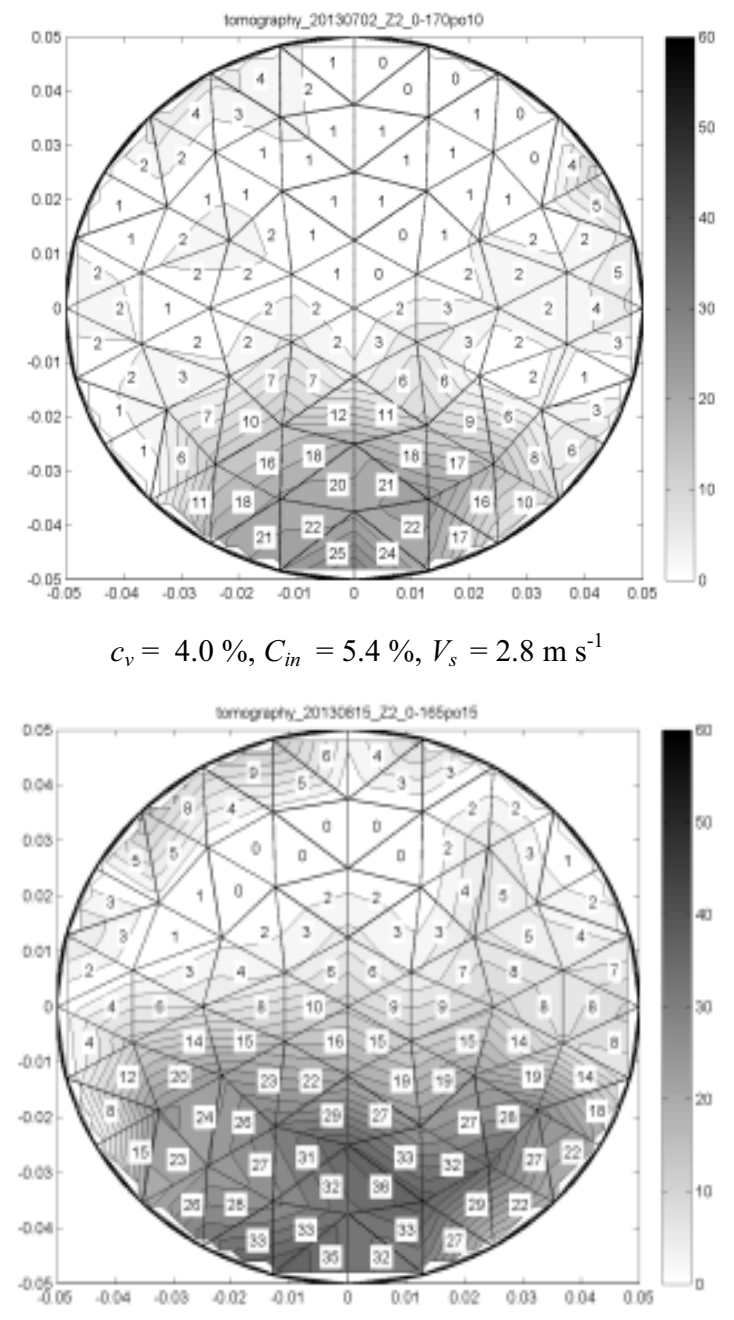

$$
c_{v}=10.5 \%, C_{i n}=12.1 \%, V_{s}=3.8 \mathrm{~m} \mathrm{~s}^{-1}
$$

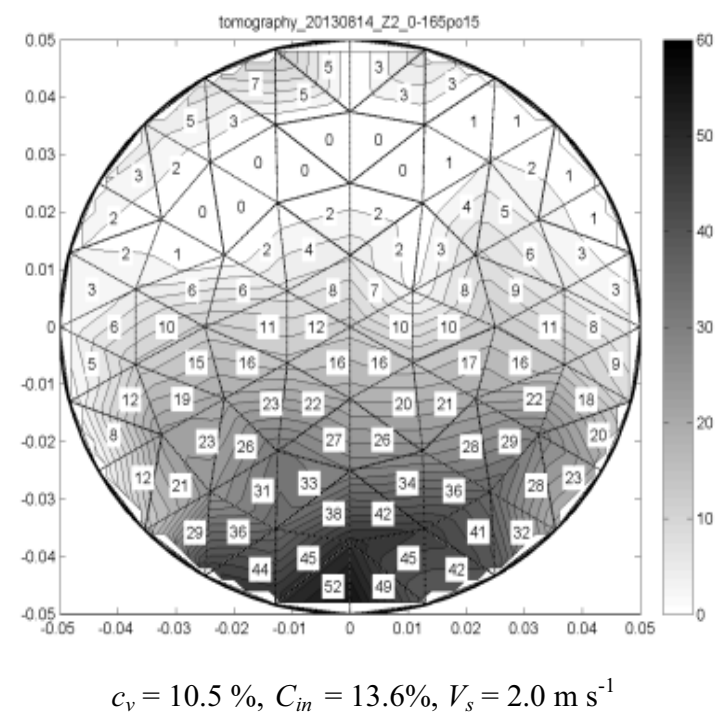

Fig. 8. Maps of local volumetric concentration distribution in horizontal pipe section, $D=100 \mathrm{~mm}$.
From observed local concentration map, see figure 8, it is evident that conveyed particles tended to occupy the bottom part of the pipe. Concentration near the pipe lateral walls was observed slightly less than in central portion of the pipe cross-section. Some errors were detected near the pipe top due to the strong effect of pipe material on $\gamma$-ray absorption. There is no reason for increasing concentration near top of the pipe, especially for lower flow velocities.

Observed concentration maps are in good agreement with these measured for mixtures of different solid materials with smaller particles (Sobota et al. [31], Przewlodzki et al. [32]).

Local concentration measurement made possible to evaluate real in situ concentration and compare it with transport concentration, measured by the vertical U-tube (B) or sampling device (5). The transport concentration $c_{v}$ depends on mixture flow velocity and particle velocity, and regarding to relative high slip velocity (e.g. velocity difference between absolute particle velocity and carrier liquid velocity), the difference between transport and in situ concentration could be important for coarse particle mixtures.

Measured values of transport concentration show significant dependence on mixture velocity. For the same solid charge transport concentration in horizontal pipe increased with increasing flow velocity, because more particles passed to saltation movement and reached higher velocity than particle sliding or rolling along the pipe invert [33].

It is evident from mutual comparison that difference between in situ and transport concentration decreases with increasing flow velocity. Significant stratification and formation of a bottom layer (movable or even stationary bed) is typical for low flow velocity of heterogeneous mixtures. It causes that particles moved relatively very slowly compare with carrier liquid velocity (see chapter: 4 Mixture flow behaviour). However, the in situ concentration value is determined by total volume of particles occurred in considered volume, without exception if they are moving or not, while transport concentration covered the conveyed particles only.

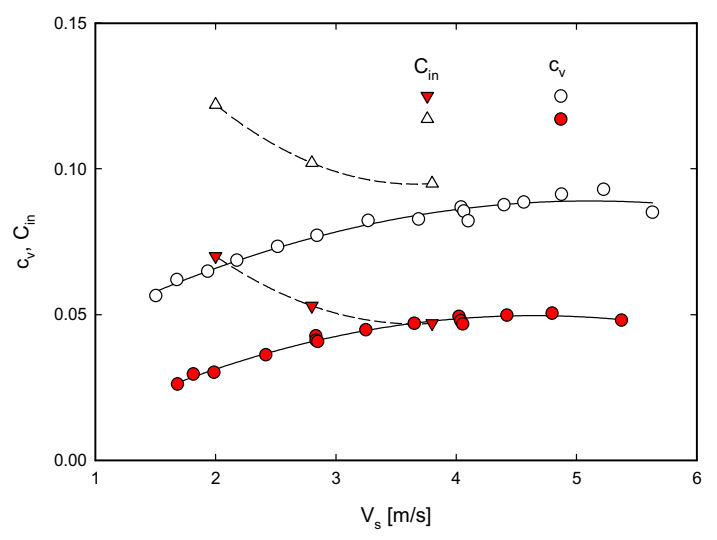

Fig. 9. Effect of mixture mean velocity, $V_{s}$, on transport, $c_{v}$ and in situ, $C_{i n}$, concentration in the horizontal pipe section. Basalt pebble-water mixture, $D=100 \mathrm{~mm}$. 
From figure 9 it is evident that transport concentration reached about $50 \%$ of in situ concentration only for mixture velocities less than $2 \mathrm{~m} \mathrm{~s}^{-1}$. For high mixture velocities, $V_{s}$ about $4 \mathrm{~m} \mathrm{~s}^{-1}$, values of both, transport and in situ concentration were practically the same, since all particles were conveyed by velocity close to carrier liquid mean velocity, and local concentration near the horizontal pipe invert was in range from 20 to $40 \%$.

\subsection{Local concentration maps - vertical pipe}

Local concentration measurement in the vertical pipe section illustrated effect of particle fall velocity on mixture concentration, see figure 10 . The in situ concentration reached higher value in ascending section than in descending section, since the fall velocity decreased (increased) the absolute particle velocity, increased (decreased) particle slip velocity in ascending (descending) section, and thus the particles remained in respective volume longer (shorter) time.

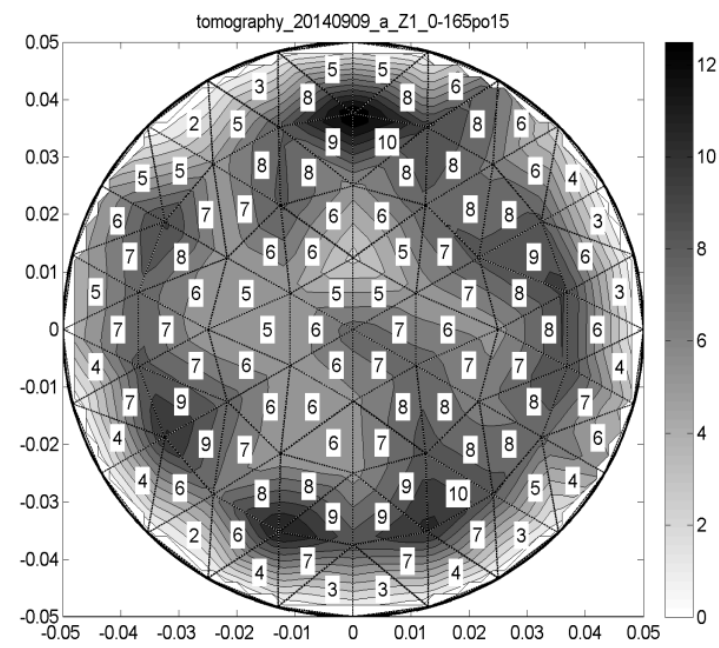

ascending pipe, $C_{i n}=6.3 \%$

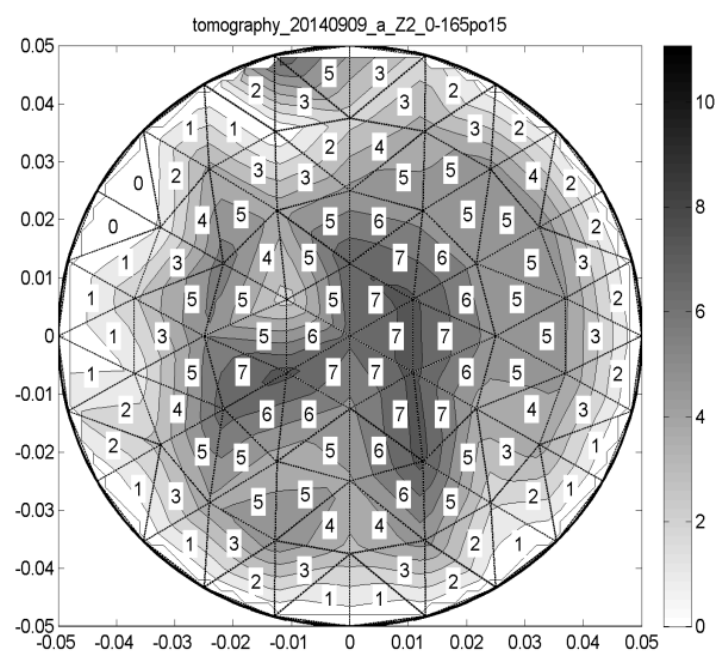

descending pipe, $C_{\text {in }}=3.7 \%$

Fig. 10. Maps of local volumetric concentration distribution in vertical pipe, $V_{s}=2.05 \mathrm{~m} \mathrm{~s}^{-1}, c_{v}=4.5 \%, D=100 \mathrm{~mm}$.
Local concentration distribution was found relatively homogeneous for lower mixture velocities $\left(V_{s} \approx 2.00\right.$ $\left.\mathrm{m} \mathrm{s}^{-1}\right)$, in contrast to higher mixture velocities $\left(V_{s}>2.80\right.$ $\mathrm{m} \mathrm{s}^{-1}$ ), where probably effect of internal circulation (due to bend effect) evoked asymmetrical distribution in horizontal direction, e. g. local concentration in the right hand portion reached higher values (about 2-3\%) than in the left hand side. In perpendicular "vertical" direction the local concentration distribution was found to be relatively symmetrical even for higher velocity values.

The flow pattern and concentration distribution were observed different in ascending and descending pipe section. For descending pipe section the concentration reached maxim in central portion of the pipe, in the direction to the pipe wall local concentration fluently decreased, and it was very low near the pipe wall. In ascending pipe section, for low flow velocities the maximum concentration was located in an annulus from about $h=0.15 D$ to $h=0.30 D$, with increasing flow velocity the width of annulus also increases, and for flow velocity $V_{s}>3.80 \mathrm{~m} \mathrm{~s}^{-1}$ the difference of local concentration in central portion and region with maximum concentration is not significant.

\section{Conclusions}

The effect of slurry velocity and concentration on the flow behaviour of coarse particle - water mixtures was studied in horizontal, vertical, and inclined smooth pipe of inner diameter $D=100 \mathrm{~mm}$.

The visualization and local concentration measurements revealed that the coarse-grained particlewater mixtures in the horizontal and inclined pipe sections were significantly stratified. The particles moved principally in a layer close to the pipe invert, for higher and moderate flow velocities particle saltation becomes dominant mode of particles movement.

Frictional pressure drop in vertical pipe was found to be less than in horizontal pipe; the almost negligible influence of the large particles on the frictional pressure drop in vertical pipe was not confirmed.

Frictional pressure drop in inclined ascending pipe section increased (compare to the horizontal pipe section) with increasing inclination angle up to about 30 degrees, and then gradually decreased. The effect of pipe inclination increased with decreasing mixture velocity.

Measurement of the local concentration distribution in the horizontal pipe confirmed that for coarse-grained mixtures the local concentration tends to approach zero in the upper portion of the pipe (from 35 to $65 \%$ of the pipe cross-section), a nearly linear concentration distribution can be recognized in the lower portion of the pipe. The concentration in the bed layer increased with increasing mean concentration and decreasing flow velocity.

Concentration distribution in ascending and descending vertical pipe section confirmed effect of fall velocity on particle-carrier liquid slip velocity and higher in situ concentration in ascending pipe section. 


\section{Acknowledgements}

Supports under the project P105/10/1574 of the Grant Agency of the Czech Republic, and RVO: 67985874 of the Academy of Sciences of the Czech Republic are gratefully acknowledged.

\section{References}

1. P. Vlasak, Z. Chara, Proc. 7th ISOPE-OMS, Lisbon (Portugal), 188 (2007)

2. P. Vlasak, Z. Chara, B. Kysela, J. Sobota, Proc. 9th ISOPE - OMS, Maui (USA), 158 (2011)

3. P. Vlasak, B. Kysela, Z. Chara, J. Hydrol. Hydromech., 60, 115 (2012)

4. D.M. Newitt, J.F. Richardson, M. Abbott, R.B. Turtle, Trans. Inst. Chem. Engnrs, 33, 93 (1955)

5. K.C. Wilson, R.S. Sanders, R.G. Gillies, C.A. Shook, Powder Technol., 197, 247 (2010)

6. C.S. Campbell, A.S. Francisco, Z. Liu, Int. J. Multiphase Flow, 30, 199 (2004).

7. K.C. Wilson, Proc. HYDROTRANSPORT 4, Banff (Canada), Paper A1 (1976)

8. R.G. Gillies, C.A. Shook, K.C. Wilson, Can. J. Chem. Eng., 69, 173 (1991).

9. V. Matousek, J. Krupicka, J. Hydrol. Hydromech., 57, 191 (2009)

10. R. Durand, Houille Blanche, 8(2): 296 (1953)

11. C.A. Shook, M.C. Roco, Slurry Flow: Principles and Practice (Butterworth/Heinemann, 1991)

12. K.C. Wilson, N.P. Brown, M. Streat, Proc. HYDROTRANSPORT 6, Canterbury (U.K.), 1, 269 (1979)

13. D.T.Y. Kao, L.Y. Hwang, Proc. HYDROTRANSPORT 6, Canterbury (U.K.), 1, 57 (1979)

14. R.J. Sumner, M. McKibben, C.A. Shook, J. Solid Liquid Flow, 2, 33 (1990)

15. P. Vlasak, Z. Chara, J. Krupicka, J. Konfrst, J. Hydrol. Hydromech. 62, 241 (2014)

16. J. Krupicka, V. Matousek, Proc. 2nd IAHR Europe Congress, Munich (Germany), (2012)

17. P. Vlasak, Z. Chara, J. Konfrst, J. Sobota B. Kysela, Proc. Tenth (2013) ISOPE-OMS, Szcezecin (Poland), 215 (2013)

18. P. Vlasak, Z. Chara, J. Konfrst, B. Kysela, Proc. 16th Int. Conf. Transport \& Sedimentation of Solid Particles, Rostock (Germany), 265 (2013)

19. D.M. Newitt, J.F. Richardson, B.J. Gliddon, Trans. Inst. Chem. Engineers, 39, 93 (1961)

20. J.S. Chung, G. Yarim, H. Savasci, Proc. Eight (1998) ISOPE Conf., Montreal (Canada), 58 (1998)

21. D.B. Sumardi, J.S. Chung, Proc. $4^{\text {th }}$ PACOMS-96, Pusan (Korea), 217 (1996)

22. R.C. Worster, D.F. Denny, Proc. Inst. Mech. Engrs., 169, 563 (1955)

23. P. Vlasak, Z. Chara, J. Konfrst, J. Krupicka, Proc. 24th(2014) ISOPE Conf., Busan (Korea), 66 (2014)

24. P. Vlasak, Z. Chara, B. Kysela, J. Konfrst, Proc. ASME 2013 - FEDSM2013-16452, Incline Village, Nevada (USA), (2013)
25. N. Loukertchenko, Z. Chara, P. Vlasak, J. Hydraulic Research, 44, 70 (2006)

26. N. Lukerchenko, S. Piatsevich, Z. Chara, P. Vlasak, J. Hydrol. Hydromech, 57, 100 (2009)

27. P. Vlasak, Z. Chara, Part. Sci.Technol, 29, 53 (2011)

28. F.J. Pugh, K.C. Wilson, Powder Technol., 104, 221 (1999)

29. D.R. Kaushal, Y. Tomita, Powder Technol., 172, 177 (2007)

30. V. Matousek, JHE ASCE, 135, 1101 (2009)

31. J. Sobota, P. Vlasak, G. Strozik, F. Plewa, Eighth ISOPE-OMS, Chennai (India), 220 (2009)

32. K. Przewlocki, A. Michalik, K. Wolski, K. Korbel, Proc. HYDROTRANSPORT 6, Canterbury (U.K.), 1, 105 (1979)

33. P. Vlasak, B. Kysela, Z. Chara, Part. Sci. Technol., 32, 179 (2014) 